\title{
INTELLIGENT DECISION SUPPORT SYSTEMS FOR ADMISSION MANAGEMENT IN HIGHER EDUCATION INSTITUTES
}

\author{
Rajan Vohra ${ }^{1} \&$ Nripendra Narayan Das ${ }^{2}$ \\ 1. Prosessor, Department of Computer Science \& Engineering, Bahra University, \\ Solan, Himachal Pradesh, India. \\ 2. Assistant Professor, Department of Computer Science \& Information Technology, \\ ITM University, Gurgaon, Haryana, . India
}

\begin{abstract}
On the basis of their use, the DSS has received positive feedback from the University's decision makers. Making use of Intelligent Decision Support Systems (IDSS) technologies suited to provide decision support in the higher education environments, by generating and presenting relevant information and knowledge which are helpful in taking the decision regarding admission management in higher education colleges or universities. The university decision makers' needs and the DSS components are identified with the help of survey done.

In this paper the components of a decision support system (DSS) for developing student admission policies in higher education institute or in the university and the architecture about DSS based on ERP are proposed followed by how intelligent DSS in conjunction with ERP helps to overcome the drawbacks, if ERP is used alone in higher education institutes.
\end{abstract}

Key-Words: - Intelligent systems, Decision support, Decision Support Systems (DSS), ERP, Higher education institutions, knowledge base.

\section{INTRODUCTION}

As we know that education is one of the most important issues all over the world. The context is a comprehensive scenario in which institutes compete for higher enrollment with each other. Now a day's, DSS are the most efficient tool to deal with any kind of situation, where the decisions are required to be taken efficiently.

This results in need for the support for various phases in the admission process. Enterprise Resource Planning (ERP) systems provide a solution due to fragmented databases, Revenue tracking, centralization, inventory optimization etc...ERP can be used together with intelligent DSS for admission management in higher education. In Admissions process, the phases related to the generation of information are as follows:

1. Application for a Course.

2. Examination.

3. Assessment \& Evaluation.

4. Selection of Students

DOI : 10.5121/ijaia.2011.2406 
International Journal of Artificial Intelligence \& Applications (IJAIA), Vol.2, No.4, October 2011

Large numbers of frameworks or topologies have been proposed for organizing our knowledge about decision support systems [1]. Five generic categories based on the dominant technology component are proposed, including Communications-Driven, Data-Driven, Document-Driven, Knowledge-Driven, and Model-Driven Decision Support Systems.

In higher education environments, Data Mining and DSS are well suited technologies to provide decision support by generating and presenting the relevant information and the knowledge towards quality improvement of education processes [2]. In this present paper the authors present the conceptual framework that can provide the required decision support especially while planning for taking the decisions in higher education management. This includes a brief discussion of the DSS model analysis for higher education systems.

\section{ERP Systems and Decision Support Systems}

ERP means the techniques and concepts for integrated management of business as a whole, from the viewpoint of effective use of management resources to improve the efficiency of enterprise management. ERP systems have 3 main limitations:

1. Without the help of programmer, the managers cannot generate custom reports and this inhibits them from obtaining information quickly.

2. ERP systems do not provide past information. ERP only provides current status. But for better decision making current as well as past (historical data) status are required.

3. As in ERP the data is not integrated with other enterprise and does not include the external intelligence.

As we know that DSS are designed for unstructured and semistructured activities. The decision process is not a single task rather it can be defined as a collection of correlated tasks that include: gathering, interpreting and exchanging information; creating and identifying scenarios choosing among alternatives, and implementing and monitoring [3] a choice. But implementing DSS is a challenging activity. Some of the disadvantages of DSS are:

1.Implementing DSS may reinforce the rational perspective and overemphasize decision processes and decision making. Traditional DSS are feeble in expressing and integrating the knowledge. Therefore there is a difficulty in solving complex unstructured and semi structured activities, and this is a limitation for taking the better decision

2. The primary components of a decision support system are a database management system, a model-base management system, and a generation and management system. An appropriate database management system must be able to work with both data that are internal to the organization and data that are external to it. The lack of integration data also leads to unsuccessful applications of traditional DSS.

In order to get an accurate, effective and better decision making, the data must be comprehensive, accurate and up-to-date. These properties require that not only data from other enterprise but also from external sources. In order to use the data from ERP systems to support decision making, some kind of intelligence is required. 
To remove the drawbacks of ERP systems and DSS as described above, IDSS are used. IDSS is a result of combining DSS and artificial intelligent (AI). Its basic design is to combine the knowledge reasoning techniques of AI and the basic function models of DSS. IDSS is needed and is economically feasible for generic problems that require repetitive decisions. IDSSs are interactive computer-based systems that use data, expert knowledge and models for supporting data mining in organizations to solve semi structured problems by incorporating artificial intelligence technique [4].Many IDSS implementations are based on Expert Systems. In addition, to the domain of higher education management, an IDSS should be able to incrementally perform simulation and prediction in key areas of application like:

- Decentralization.

- Opening of Satellite Centers.

- Profitability Analysis.

- Revenue Profiling.

- Student Profiling.

- Profiling Loan Applicants.

- Identify High Revenue Courses \& Outlier Courses.

- Collaboration models with similar institutes.

- Planning Outsourcing

- Framing Admission Policies

\section{Designing a framework of IDSS based on ERP systems in higher education}

\section{A. Proposed framework of IDSS based on ERP systems}

To enhance the ranking of the institutes, so that more students will take admissions in their institutes/ universities, universities try to apply strategies and develop new instruments to improve the quality of teaching and research activities and provide the communities with relevant services and knowledge.

Information and communication technologies (ICT) are increasingly becoming essential parts of the modernized lifestyles. ICT is increasingly becoming very important for supporting decision making processes [5].

GIS based educational decision making system is open to the public to assist education decision making. Various information query and display methods are provided in the system, including browsing, text-based query and display, and spatial query and display [6].The framework of ERPbased decision support system could be a very good mode to help businesses take full advantage of the data in ERP systems to support decision-making and improve the capabilities of decision support system [7]. The data in ERP systems reflects details of the current daily transaction processing, which has good character of real-time and dynamics.

The system dynamic model can be applied for solving a wide range of problems related to academic capacity planning, such as:

a) Determining the faculty's admission capacity for a specific degree setting and specific resource scenario; 
International Journal of Artificial Intelligence \& Applications (IJAIA), Vol.2, No.4, October 2011 b) Allows management to investigate changes in the key academic resource management processes before implementing any policy changes; Computing the necessary adjustment of admission number or teaching resources for supporting a certain scenario, such as reduction in funding; or

d) Obtain insights on the likely impact of funding, resource management or academic policy on academic resources and quality.[8]

One of the limitations of ERP systems is that the database of ERP has only the current status of data. Since the historical data is also required, therefore to make use of that, IDSS framework is used as shown in figure. The knowledge base of the expert systems is independent of the database of ERP systems. Any of the AI techniques like ANN or Genetic Algorithms can be used to integrate ERP database with Expert systems. The framework is shown below:

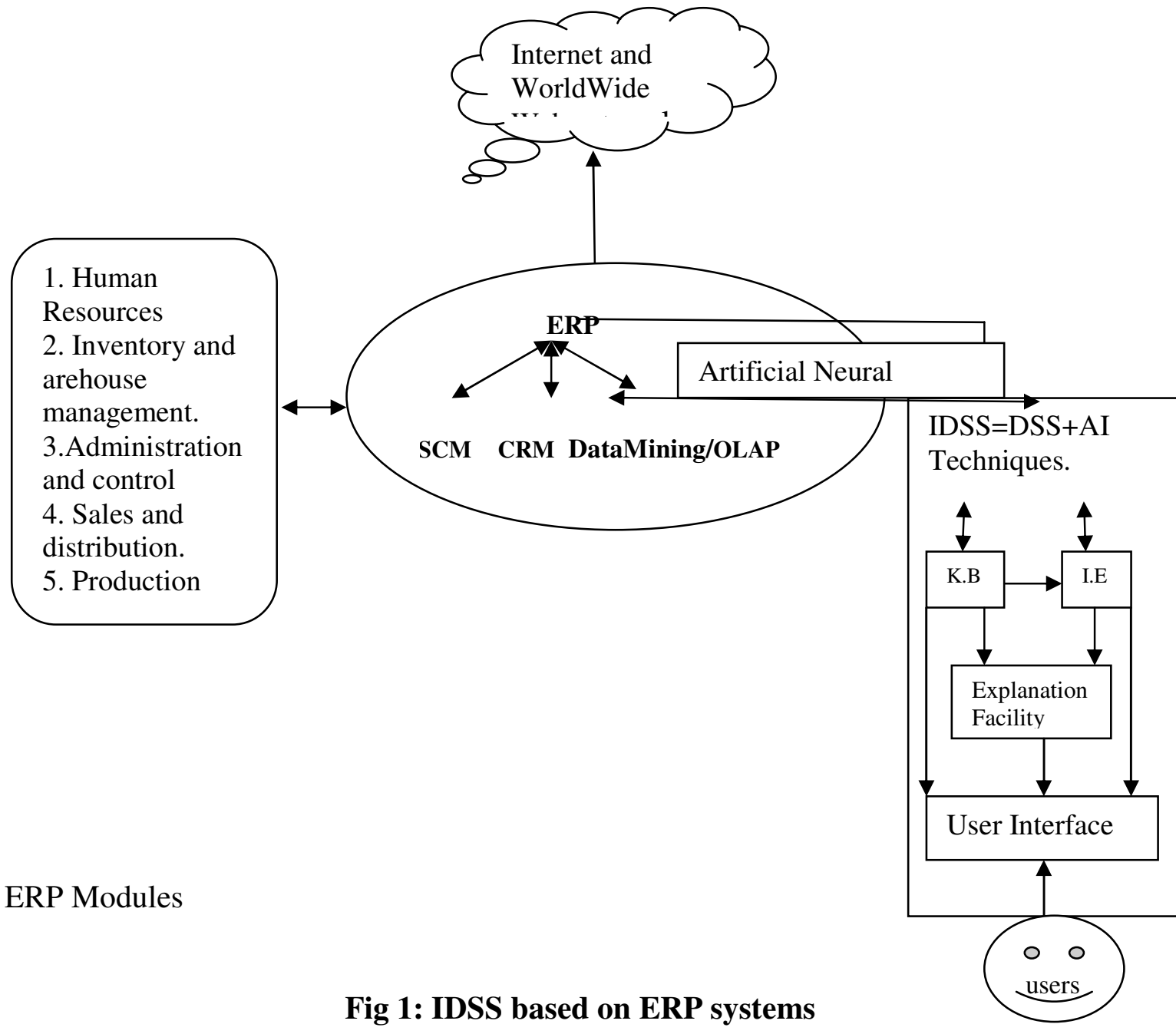

\section{b. Functioning of IDSS based on ERP systems for admission management}


ERP Systems provide support for OLTP in these phases. The building of a Data Warehouse and application of Data Mining techniques enables Intelligent Decision Support.

Extraction, transformation and loading (ETL): ETL is a process in database usage and especially in data warehousing that involves extraction of data from outside sources, transforming it to fit operational needs and loading it into the end target i.e database or data warehouse.

The Decision Support for such an IDSS can provide Decision Support in:

1. Segregating Applicants into similar Groups, based on Region, Academic Profile and Economic factors like Income.

2. Estimate the Cut off Percentage and Rank and perform a comparative historical analysis.

3. Predict whether an applicant's academic profile matches with that of its existing students.

4. Identify Students with Loan Requirements and send this data to lending agencies.

5. Perform Profitability Analysis for the institute.

6. Identify Outlier Students.

7. Target Marketing for Campaign Management in Promising regions/ students.

8. Gather Competitive Intelligence (CI) on Business rivals.

9. Demographic Analysis capabilities to study Admitted / Applicant Students and the local Demography.

10. Capacity Planning of Hostel accommodation.

11. Route Planning \& Capacity utilization of Transport Systems.

For the creation of a IDSS in higher education, appropriate academic analytic tools automated or manual are required to gather, synthesize, and evaluate relevant data and information for effective decision making. All the knowledge is stored in knowledge base, an important component of IDSS architecture. If data collection is done with surveys, questionnaire etc. then it is called manual collection of data.

The collected data can then be utilized to evaluate quality, performing analysis and suggest alternatives for decisions. In solving the admissions relating issues, there are several activities that should be taken into consideration for the decision processes as presented in Table 1 . 
International Journal of Artificial Intelligence \& Applications (IJAIA), Vol.2, No.4, October 2011

DSS MODULE

STUDENT MODULE

\section{DECISIONAL} SITUATION

\begin{tabular}{|l|l|}
\hline Students' enrollment & Faculty \\
\hline $\begin{array}{l}\text { Choosing a Specialization } \\
\text { (Course/ Branch) }\end{array}$ & Scholarship \\
\hline Studies reclassification & Career guidance \\
\hline Recognition & $\begin{array}{l}\text { Web Information and } \\
\text { announcements }\end{array}$ \\
\hline Tuition fees & Hostel facility \\
\hline Ranking of college & Transportation \\
\hline Infrastructure & Library \\
\hline Interruption of studies(BUNK) & Extension of studies \\
\hline Tutorial activities & Parking facility \\
\hline Health facility & Research facility \\
\hline
\end{tabular}

\section{Table 1: Decisional Situations in which Decisions are required.}

While these modules can generate the reports required by MIS, the decision support capabilities required, that are described above, can only be generated by IDSS. The proposed conceptual framework is made up of 5 parts as shown below Fig 2:

1. The Database Management System: The Database Management Component stores information which can be further subdivided into that are derived from an organization's traditional data repositories, from external sources such as the Internet, or from the personal insights and experiences of individual users. Example includes student personal information, student database, results database.

2. The Model Management System: The Model Management Component handles representations of events, facts, or situations using various kinds of models, two examples being optimization models and goal-seeking models. Examples include probabilistic models, queuing models, econometric model. Models facilitate What if Analysis like Demographic Analysis, Demographic Analysis etc. Such Models include Regression Model.

3. The Knowledge Base: Knowledge base component consists of one or more intelligent systems. Like data and model management software, knowledge management software provides the necessary execution and integration of the intelligent system. A DSS that includes such a component is called an intelligent DSS, an expert support system, active DSS or knowledgebased DSS. Examples include the academic profile of students, evaluation criteria, segregation rules like skill sets, percentage marks etc. The Knowledge base can be used to store Data, Heuristics, meta knowledge etc, pertaining to the Domain of Application. Such a Knowledge base 
International Journal of Artificial Intelligence \& Applications (IJAIA), Vol.2, No.4, October 2011 can be manipulated by Intelligent Decision Support Systems like Expert Systems, Neural Networks, Fuzzy Logic Systems \& Genetic Algorithms also.

4. The user interface: The user interface subsystem is that component of a computer system that allows bidirectional communication between the system and its user. It includes not only the hardware and the software but also the factors that deal with ease of use, human-machine interactions.

5. Users: Finally the users use IDSS for taking the decisions through user interface.

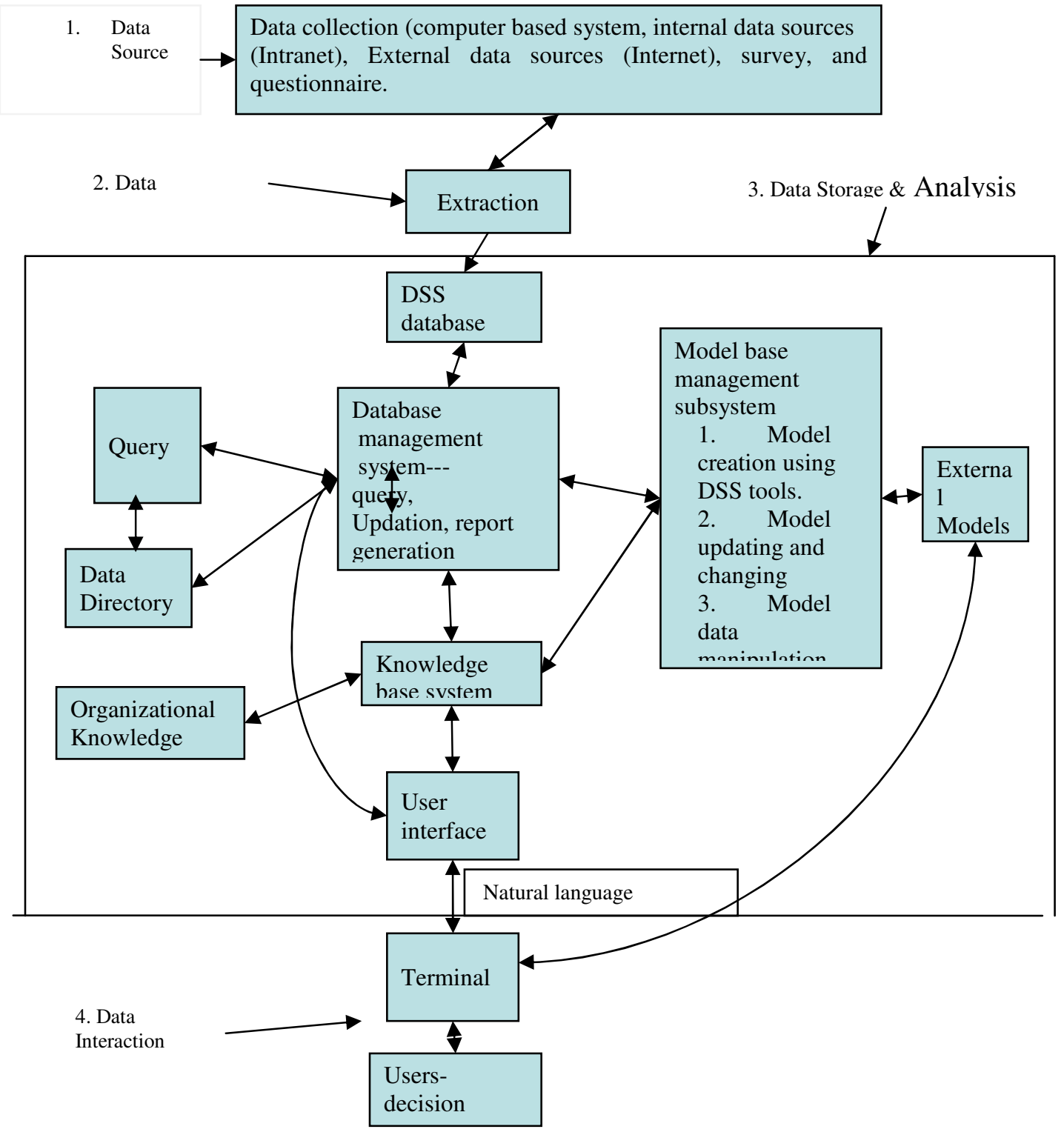

Fig 2: A schematic view of DSS for admissions in higher institutes. 
International Journal of Artificial Intelligence \& Applications (IJAIA), Vol.2, No.4, October 2011

\section{Conclusions}

In this paper, the authors illustrated the activities regarding admissions in the higher institutes where decision support systems are required for taking the admissions. The final section comprises the proposed architecture of Decision Support System, a modern approach to the decision making processes. ERP with IDSS provides good support for decision making otherwise the limitation of ERP will reduce the effectiveness system of decision making.

Future work will focus on implementing the proposed architecture for the education system.

In addition Specific Data Mining Techniques like Clustering can Profile Student intake and identify Promising Groups for Targeting in future intakes. Decision Trees can identify Loan needy students. Integrated educational Planning in the area can thus be facilitated by drilling down the Data to Schools in the area.

\section{References:}

[1] D. J. Power, "Supporting Decision-Makers: An Expanded Framework", In Harriger, A.(Editor), eProceedings Informing Science Conference, Krakow, Poland, June 19-22, 2001, 431-436.

[2] Vasile Paul Bresfelean et. al ,"Towards the development of decision support in academic environments," proceedings of the ITI $2009,31^{\text {st }}$ international conference on information technology interface, june 22-25, 2009, Cavtat, Croatia

[3] G. DeSanctis and R. B.Gallupe, "A Foundation for the Study of Group Decision Support Systems", Management Science, 33(5), 1987, 589-609.

[4]. Marco Semini, Håkon Fauske and Erik Gran "Use of model-driven decision support methods for supply chain design" SINTEF Technology and Society.

[5]. Muneer Alsurori, Juhana Salim," Information and Communication Technology for Decision-Making in the Higher Education in Yemen: A Review" 2009 International Conference on Electrical Engineering and Informatics ,5-7 August 2009, Selangor, Malaysia.

[6] Wang Aihua, Guo Wenge, Xu Guoxiong, Jia Jiyou, Wen Dongmao," GIS-Based Educational DecisionMaking System" Proceedings of 2009 IEEE International Conference on Grey Systemss and Intelligent Services, November 10-12, 2009, Nanjing, China., 2009 IEEE, pp 1198-1202.

[7]. Qiusheng Liu, Guofang Liu," Research on the Framework of Decision Support System Based on ERP Systems", 2010 Second International Workshop on Education Technology and Computer Science, 2010 IEEE.

[8]. S. F. Mohd Dahlan and N. A. Yahaya,"A System Dynamics Model for Determining Educational Capacity of Higher Education Institutions" Second International Conference on Computational Intelligence, Modelling and Simulation, 2010 IEEE.

[9] P. G. W. Keen and M. S. Scott Morton, "Decision Support Systems: An Organizational Perspective", Reading, MA, Addison-Wesley, 1978. 